\title{
One-trial context fear conditioning as a function of the interstimulus interval
}

\author{
RICK A. BEVINS \\ University of Kentucky, Lexington, Kentucky \\ and \\ JOHN J. B. AYRES \\ University of Massachusetts, Amherst, Massachusetts
}

\begin{abstract}
In two experiments, we examined the effects of a wide range of interstimulus intervals $(2.5,15,45$, 120,135 , and $405 \mathrm{sec}$ ) on one-trial context fear conditioning with rats. Here, the interstimulus interval (ISI) denotes the time between placement in a conditioning chamber and the onset of a single footshock. On the conditioning day, we observed that the rats' behavior at the time of shock onset varied systematically across ISI values. On the subsequent test day, we used context-evoked freezing as a measure of context conditioning and found the well-known inverted U-shaped ISI function. We also found that conditioned freezing for the shortest ISI values was concentrated early in the test session, whereas freezing at longer ISIs was distributed more evenly throughout the test session. The freezing results found here are more consistent with the literature on conditioning with punctate cues than are previously described results from one-trial context fear-conditioning procedures.
\end{abstract}

Conditioning to a punctate conditioned stimulus (CS) varies with the time between the onset of that $\mathrm{CS}$ and the onset of an unconditioned stimulus (US). This interval of time is termed the interstimulus interval (ISI). In most conditioning situations there is an optimal ISI. As the ISI is increased up to this value, conditioned performance increases. As the ISI is further increased, conditioned performance declines. This ISI function (inverted U) is a very general result in Pavlovian conditioning and has been found in such diverse preparations as siphon withdrawal in Aplysia (Hawkins, Carew, \& Kandel, 1986), sign tracking in pigeons (Gibbon, Baldock, Locurto, Gold, \& Terrace, 1977), nictitating membrane response conditioning in rabbits (Smith, Coleman, \& Gormezano, 1969), conditioned suppression in rats (Yeo, 1974), and human eye-blink (McAllister, 1953).

Unlike the preparations just mentioned, much less is known about the effects of ISI manipulations on one-trial context fear conditioning. Blanchard, Fukunaga, and Blanchard (1976) found that rats given a single footshock 2 min after placement in a box (2-min ISI between context and US) were subsequently much less active in that

Experiment 1 was part of a dissertation submitted by R. A. Bevins to the University of Massachusetts in partial fulfillment of $\mathrm{PhD}$ requirements. Funds provided by a Faculty Research Grant from the University of Massachusetts and Grant MH50491 from NIMH to J. J. B. Ayres supported this research. Correspondence and requests for reprints should be sent to R. A. Bevins, Psychology Department, Kastle Hall, University of Kentucky, Lexington KY 40506-0044 (e-mail: rabevi00@ukcc.uky.edu).

$$
\text { - Accepted by previous ediror, Vincent M. LoLordo }
$$

box than rats that received the same shock immediately after placement in the context $(0-$ sec ISI between context and US). Fanselow (1986, 1990; Fanselow, DeCola, \& Young, 1993) has repeatedly demonstrated a similar data pattern using context-evoked freezing as an index of conditioning and has coined the term "immediate-shock deficit" to describe the apparent lack of conditioning following the immediate-shock procedure (see also Fanselow, Landeira-Fernandez, DeCola, \& Kim, 1994).

Fanselow and his co-workers have characterized the immediate-shock deficit as complete (immediate shock produces no context conditioning). The results of Blanchard et al. (1976) and more recently of Bevins and Ayres (1994), however, suggest that the deficit might be better described as partial (immediate shock produces less conditioning than delayed shock but still produces some conditioning). This suggestion is based on Blanchard et al.'s finding that although movement in the immediate-shock group was significantly greater than that in the delayed-shock group, it was significantly less than that in a no-shock control group. A similar data pattern was reported by Bevins and Ayres using contextevoked freezing as the measure of conditioning.

In addition to studying the effects of immediate shock and shock delayed for $120 \mathrm{sec}$, Fanselow (1986) examined a range of ISIs including $1,3,9,27$, and $81 \mathrm{sec}$. He found no context-evoked freezing following the 1- and 3sec ISIs and found no significant difference in freezing produced by 9 versus $3 \mathrm{sec}$ or by 9 versus $27 \mathrm{sec}$. He concluded that "a substantial period of time is needed to overcome the immediate shock deficit" (Fanselow, 1986, p. 23). In a subsequent study, Fanselow (1990) used ISIs of $0,41,54$, and $162 \mathrm{sec}$. He found that stibsequent 
context-evoked freezing increased with the ISI, showing no downturn at the longest $(162-\mathrm{sec})$ value tested.

There are thus two clear differences in ISI functions described for one-trial context conditioning versus those described for other Pavlovian procedures (including onetrial Pavlovian fear conditioning to punctate CSs). First, a complete conditioning deficit with ISIs as long as 1,3, 9 , and possibly even $27 \mathrm{sec}$ contrasts markedly with evidence for one-trial excitatory fear conditioning to punctate CSs with ISIs as short as $0 \mathrm{sec}$ (Burkhardt \& Ayres, 1978; Heth \& Rescorla, 1973; Mahoney \& Ayres, 1976). Second, the lack of a downturn at the longest ISI tested is inconsistent with the inverted U-shaped ISI function so typical of many Pavlovian preparations (Rescorla, 1988). Of course, there might be a downturn if a longer ISI were examined.

\section{EXPERIMENT 1}

Experiment 1 assessed the effects of a wide range of ISIs $(2.5,15,45,135$, and $405 \mathrm{sec})$ on one-trial context fear conditioning as measured in terms of contextevoked freezing. The shortest ISI used $(2.5 \mathrm{sec})$ was well within the range found by Fanselow (1986) to produce a complete immediate-shock deficit. Pilot work, moreover, found that after placing the rat in the conditioning chamber, the experimenter needed $2 \mathrm{sec}$ to remove his hand and close the lid. Thus, $2.5 \mathrm{sec}$ was about as close to an immediate shock as we could get. The longest ISI studied $(405 \mathrm{sec})$ was considerably longer than the longest used by Fanselow (1986, 1990), and the question of interest was whether a downturn in the ISI function might be obtained at that value.

In addition to measuring the total amount of freezing in the test session, we also examined the temporal distribution of freezing across the test session. This examination was motivated by past work showing that the distribution of conditioned responding was sensitive to the ISI (e.g., Schneiderman \& Gormezano, 1964; see also Maes \& Vossen, 1992). Finally, the present experiment included two control conditions. One of these, the no-shock control, was the control used by Blanchard et al. (1976) and by Fanselow $(1986,1990)$ in which, on the day of conditioning, the rats receive exposure only to the training context. This procedure, which controls for the unconditioned effects of context exposure, may be viewed as analogous to a traditional CS-alone control (Rescorla, 1967). In the second control procedure (cf. Fanselow, 1986, Experiment 4A), subjects were exposed to an immediate shock (2.5-sec ISI) in a context vastly different from our standard training/test context. This procedure, which was designed to control for the unconditioned effects of shock, may be viewed as analogous to a traditional US-alone control (Rescorla, 1967).

\section{Method}

Subjects. The subjects were 70 Holtzman-descended albino rats, 85 to 109 days old, from our colony at the University of Massachusetts, Amherst. The males ( $n=35$ ) weighed from 383 to $602 \mathrm{~g}$.
The females $(n=35)$ weighed from 251 to $347 \mathrm{~g}$. The rats were housed in suspended stainless steel cages and had 24-h access to food and water. The colony was on a 16:8-h light:dark cycle. Experimental sessions were conducted during the light portion of this cycle. Each rat was handled for about $1 \mathrm{~min}$ on each of the 5 days before the study began.

Apparatus. Except for one control group (see below), a box with the inside dimensions of $19.4 \times 20.3 \times 22.2(\mathrm{~h} \times \mathrm{w} \times \mathrm{l}) \mathrm{cm}$ was used as both the conditioning and test context. The back wall and ceiling were Plexiglas with black cardboard mounted on the outside. Both end walls were glossy black. Mounted in the center of one end wall, $14 \mathrm{~cm}$ above the grid floor, was a cue light, $1.5 \mathrm{~cm}$ in diameter. The front wall was clear Plexiglas. The floor was made of 20 stainless steel rods, $2 \mathrm{~mm}$ in diameter, spaced $1.2 \mathrm{~cm}$ apart. Ambient lighting was provided by a frosted white bulb $(100 \mathrm{~W}$, $120 \mathrm{~V}$ ) mounted about $30 \mathrm{~cm}$ in front of the clear Plexiglas wall about $27 \mathrm{~cm}$ above the grid floor. The box was cleaned with a solution of $5 \%$ vinegar ( $5 \%$ acidity) and $95 \%$ tap water before each rat was conditioned or tested. A 68-dB background noise was produced by a room air conditioner. Noise level was measured with a General Radio Model 1565-B sound meter set on the Cs scale with the microphone placed in the center of the box. A high-voltage, high-resistance shock source provided a 2-sec $1-\mathrm{mA}$ footshock US scrambled through a relay sequencing scrambler (Hoffman \& Fleshler, 1962). Sessions were initiated by switches mounted in such a way as to detect floor movement. Thus, when a rat was placed in the box, the floor tilted slightly, closing the switch and starting a session.

As indicated above, one control group, Group USa, received shock in another context, termed "Box V." Located in a different room, Box V was a Gerbrands operant box housed in a $0.61-\mathrm{m}$ plywood cube lined with acoustical tile. Two metal plates were inserted in the operant box as false end walls such that they formed a truncated $V$. They were separated by $4.4 \mathrm{~cm}$ at floor level and by $22.6 \mathrm{~cm}$ at ceiling level. The front and back clear Plexiglas walls were separated by $20.3 \mathrm{~cm}$, and the ceiling was $19.2 \mathrm{~cm}$ from the floor. The floor was made of four stainless steel rods, $2 \mathrm{~mm}$ in diameter, mounted $1.3 \mathrm{~cm}$ apart. The box was cleaned with tap water before each rat was conditioned. Masking noise was provided by an $80-\mathrm{dB}$ white noise from a speaker located on the box lid. Ambient lighting was provided by a frosted red bulb $(7.5 \mathrm{~W}, 110 \mathrm{~V})$ mounted on the rear wall of the housing cube. Shock was delivered to the grid floor and to the two metal plates by the very same shock source and scrambler that supplied shock to the standard conditioning/test context ("black box").

Procedure. There were seven groups, each with 5 males and 5 females. For five of the groups on Day 1, shock was given 2.5, $15,45,135$, or $405 \mathrm{sec}$ after the rats were placed in the black box. All of these rats werc removed $30 \mathrm{sec}$ after shock offset. The two remaining groups served as controls. One control group (noshock) was treated like Group 405 but without the shock. This group controlled for the unconditioned effects of exposure to the context alone. The other control, termed "US alone" (USa), received a shock US but did not experience the black-box context on the conditioning day. Instead, it received the immediate-shock procedure ( $I S I=2.5 \mathrm{sec}$ ) in Box V. This group controlled for the unconditioned effects of exposure to shock. Besides receiving shock in a different box located in a different room, these Group USa rats were transported differently to Box V. While still in its home cage, each rat in this group was wheeled on a cart to and from its conditioning room. Each rat in the other six groups was removed from its colony home cage and carried by hand to and from its conditioning room. When each rat was removed from the home cage, it was placed on the experimenter's left arm and against his chest. Placement of each rat into the black box involved wrapping the right hand around the back of the rat and setting it into the box such that its nose pointed toward the side black wall where the inactive cue light was mounted. This place- 
ment ritual was followed for each rat on both conditioning and test days.

On Day 2, each rat (including each rat in Group USa) was carried by hand to the black box and filmed for $10 \mathrm{~min}$ with a Model AG-180 Panasonic video camera for later observation of instances of freezing. After each rat was filmed, all fecal boli were counted and removed.

Observations and data analyses. "Freezing" or "not freezing" for each rat was scored from the video tapes. "Freezing" was defined as the absence of all movement except for the breathing movements of the rat's sides. Any other movement was defined as "not freezing" (Fanselow, 1986, p. 21). Observations were paced by a $28-\mathrm{V}$ white indicator lamp placed in front of the black box. The lamp bulb (6 mm in diameter) was mounted in the center of a black metal stand $(6.0 \mathrm{~cm}$ high $\times 4.1 \mathrm{~cm}$ wide) $4.0 \mathrm{~cm}$ from the bottom. That lamp, which was shielded from the rat's direct view by the metal stand, cycled on for $0.1 \mathrm{sec}$ and off for $1.9 \mathrm{sec}$ during conditioning and testing in the black box. Thus, freezing was scored every $2 \mathrm{sec}$. Reliability of observations was assessed by a trained observer who was naive as to the rats' experimental history. The correlation between the independent observations on the 22 rats scored in common was high $(r=.96)$.

For the overall freezing and defecation results, we used two-way analysis of variance (ANOVA) with one factor being ISI value $(2.5,15,45,135$, or $405 \mathrm{sec})$ and the other being sex. Because very little freezing was observed in Groups USa and No-shock, we used the nonparametric Mann-Whitney $U$ test to compare these control groups with Group 2.5. ${ }^{l}$ These comparisons were important because more freezing and/or defecation in Group 2.5 than in the two control groups would suggest an effect not explainable in terms of the unconditioned effects of exposure to context alone or to the US alone. Such a result would imply that the immediate-shock procedure produced conditioning to the context. We used a repeated measure ANOVA for initial assessment of the within-test-session freezing data and Duncan's range tests for subsequent post hoc comparisons. A two-tail rejection region of .05 was used for all tests.

\section{Results}

Figure 1 shows the mean proportion of freezing and the median proportion of freezing (inset graph) for each group on the test day. A two-way ANOVA on the ISI groups revealed a main effect of sex $[F(1,40)=4.93]$. On average, males froze more than females at each of the ISI values. There was also a significant main effect of ISI $[F(4,40)=3.37]$. The ISI $\times$ sex interaction was not significant $(F<1)$. For the five ISI groups $(2.5-405 \mathrm{sec})$, the ISI function appeared to follow the inverted-U-shaped pattern seen in many other preparations. That is, freez-

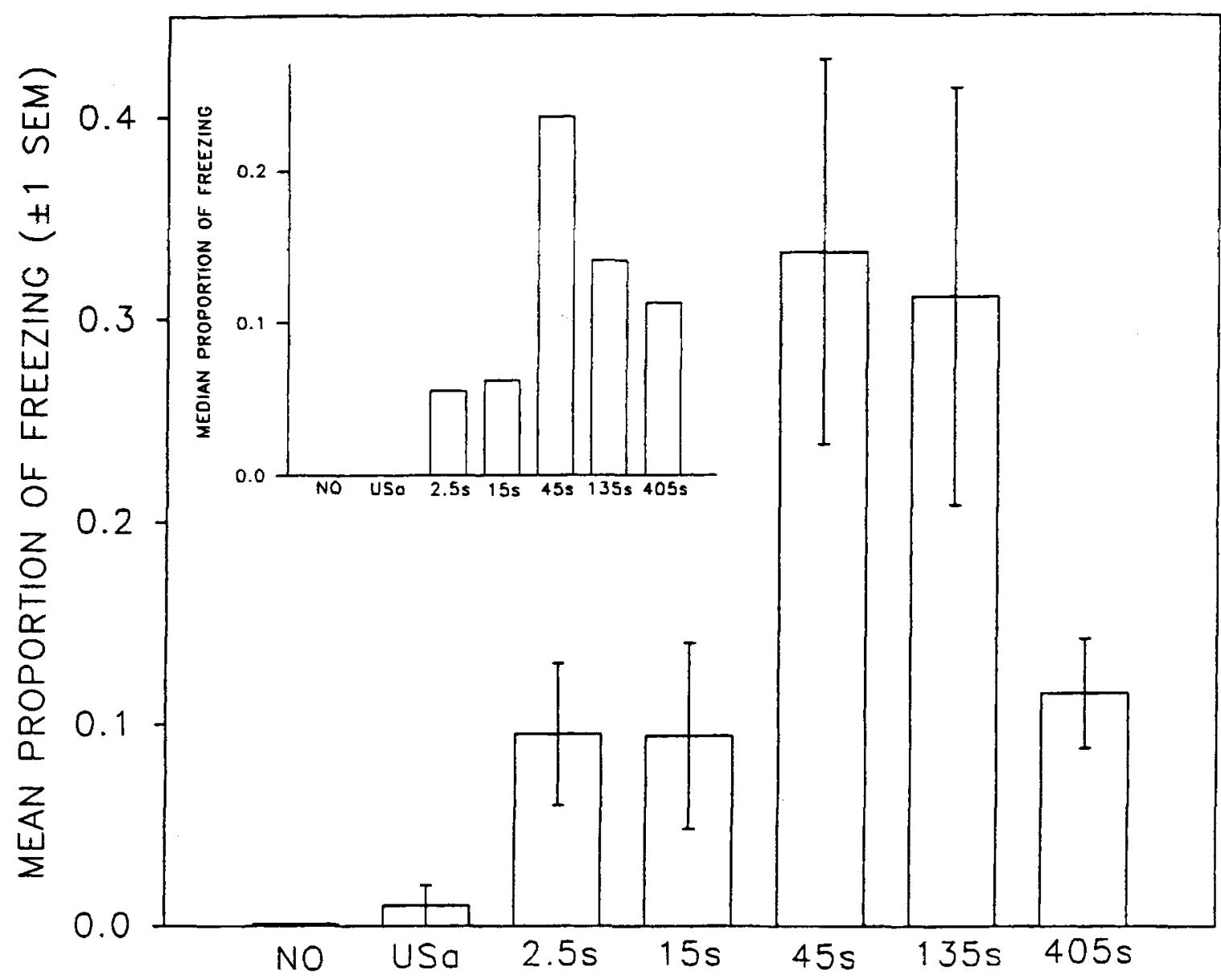

Figure 1. Mean proportion of freezing and the median level of freezing (inset graph) for each group in Experiment 1. 
ing was low at short ISI values ( 2.5 and $15 \mathrm{sec}$ ), then increased with the ISI, up to $45 \mathrm{sec}$, and then decreased beyond that value. A priori comparisons were conducted to assess this pattern. Of special interest is the question of whether the downturn at $405 \mathrm{sec}$ was significant. A comparison of Group 405 with Group 45 did indeed reveal a significant difference $[t(18)=2.21]$. The Mann-Whitney tests found significantly more freezing in Group 2.5 than in Group No-shock $(U=12)$ and Group USa ( $U=$ 24), which themselves did not differ $(U=30.5)$.

Figure 2 shows the within-session distribution of freezing for Group USa and the five ISI groups. Each

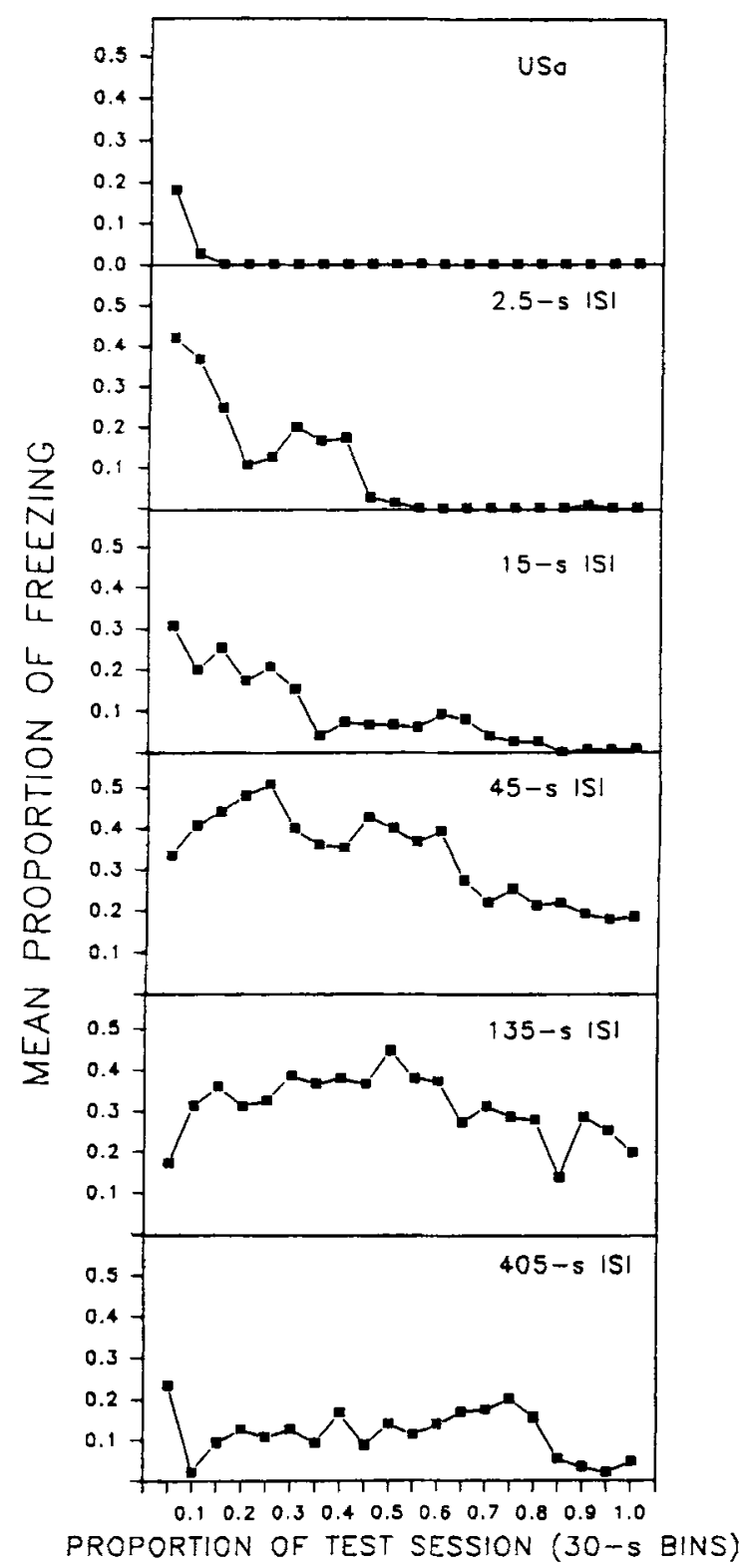

Figure 2. Mean proportion of freezing scores per 30-sec bin of the 10-min test session for each ISI group and the USa control of Experiment $\mathrm{I}$. data point denotes the proportion of samples scored as freezing for that $30-\mathrm{sec}$ interval (bin) of the 10-min test session. The small amount of freezing observed in Group USa was concentrated in the first $30 \mathrm{sec}$. For the ISI groups, as the time between placement in the box and shock on Day 1 increased, the distribution of freezing on Day 2 appeared to shift so that freezing was distributed more evenly throughout the test session. A repeated measures ANOVA revealed a significant main effect of group $[F(5,1026)=4.30]$ and bin $[F(19,1026)=8.21]$. More importantly, the group $\times$ bin interaction was significant $[F(95,1026)=2.21]$. To examine this interaction and to minimize the number of post hoc comparisons, Duncan's range tests were conducted for each minute of the test session (i.e., two $30-\mathrm{sec}$ bins averaged). In Minute 1, Group 2.5 froze more than the USa control and Group 45 froze more than all the other groups except Group 2.5. In Minute 2, Group 135 froze more than Groups USa and 405, while Group 45 froze more than any group except Group 135. Minute 3 was like Minute 2, except that Group 135 did not differ from Group 405. In Minute 4, Groups 45 and 135 froze more than Groups USa and 15. In Minutes 5 and 6, Groups 45 and 135 froze more than any of the other groups. In Minute 7 , Groups 45 and 135 froze more than Groups USa and 2.5. In Minutes 8 and 10, Group 135 froze more than Groups USa, 2.5, and 15. In Minute 9, Groups 45 and 135 froze more than Groups USa, 2.5, and 15. Although the distribution results are variable, some important trends to note for later discussion are the following: (1) The immediate shock group differed from the USa control in the first minute of testing. (2) The intermediate ISI groups (Groups 45 and 135) tended to freeze more than the USa control throughout testing. (3) Consistent differences between the intermediate ISI groups and the immediateshock group did not emerge until Minute 5. (4) The onset of freezing bouts was variable for rats in Groups 405 and 15. Indeed, those groups did not differ from the USa control at any time point.

Figure 3 shows the mean number of boli and the median number of boli (inset graph) for each group. The two-way ANOVA on the ISI groups revealed no significant main effects $(F \mathrm{~s} \leq 1.31)$. However, there was a significant ISI $\times$ sex interaction $[F(4,40)=2.88]$. Females defecated less than males at the 2.5 - and 15 -sec ISI, but defecated more at the longer ISIs ( 45 to $405 \mathrm{sec}$ ). Comparisons found more defecation in Group 2.5 than in Group No-shock $(U=10)$ but not in Group USa $(U=$ 62). Group USa also defecated more than Group Noshock $(U=20)$.

\section{Discussion}

Immediate shock in this research produced weaker freezing than delayed shock but more freezing than that resulting from the two control procedures. These results suggest that the immediate shock produced some conditioning and therefore that the immediate-shock deficit obtained here is better described as a partial deficit 


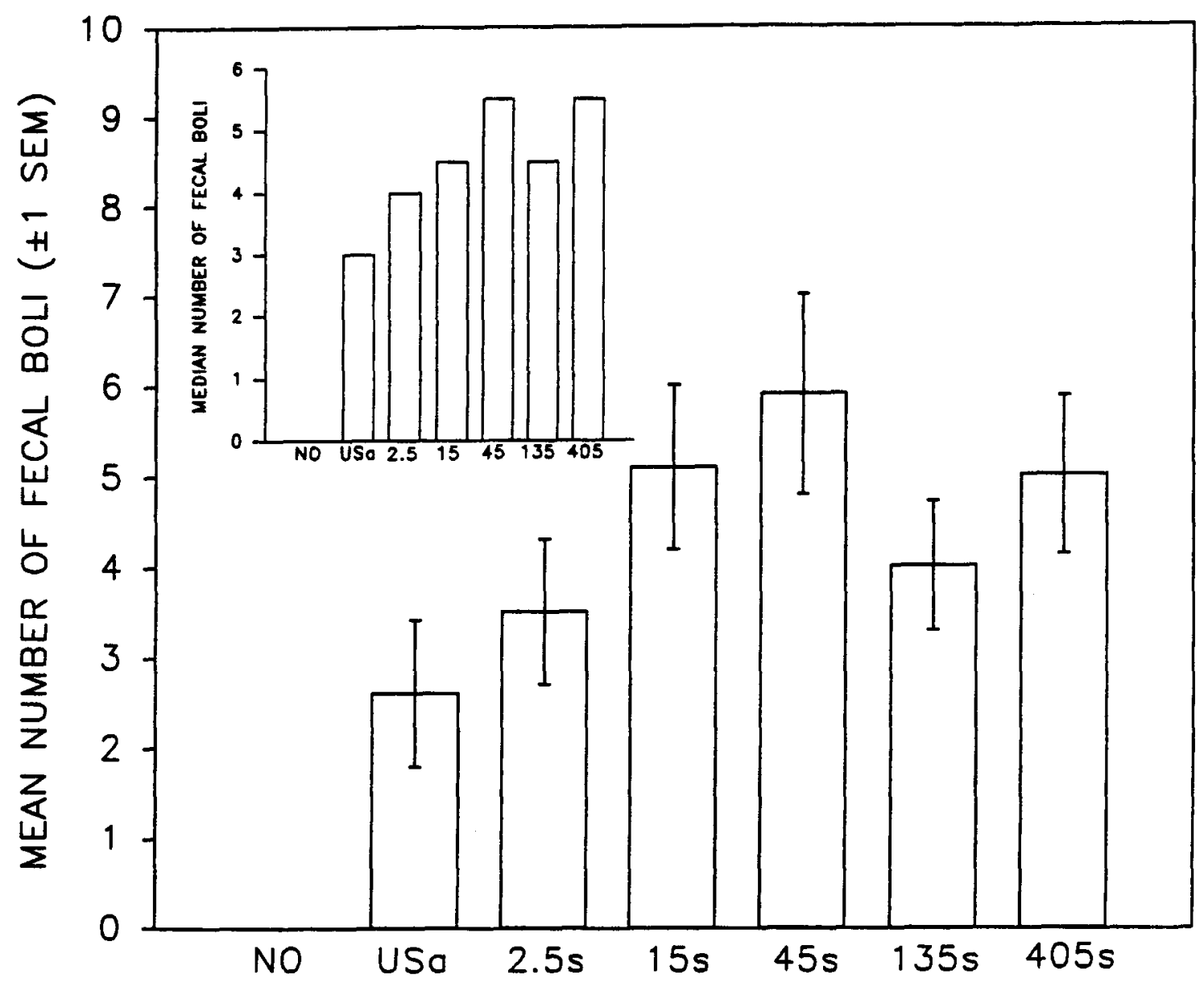

Figure 3. Mean number of fecal boli and the median number of boli (inset graph) for each group in Experiment 1.

(Bevins \& Ayres, 1994; Blanchard et al., 1976) than as a complete deficit (Fanselow, 1986, 1990). Moreover, freezing showed an inverted-U-shaped function across ISIs. This demonstration was accomplished by including an ISI $(405 \mathrm{sec})$ much longer than the longest $(162 \mathrm{sec})$ previously studied by Fanselow (1990). We also found a shift in the distribution of freezing as a function of the ISI. When the ISI was very short $(2.5$ and $15 \mathrm{sec})$, freezing was concentrated early in the session on the test day. With longer ISIs, freezing was more evenly distributed throughout most of the session. Changes in the temporal patterning of conditioned responding with changes in the ISI are well documented in such diverse Pavlovian conditioning preparations as the rabbit's nictitating membrane response (Schneiderman \& Gormezano, 1964) and aversive conditioning with goldfish (Bitterman, 1964). By stating that freezing was sensitive to the temporal position of shock, we are not claiming that a temporal mechanism per se was controlling conditioned freezing (see, e.g., Williams, Frame, \& LoLordo, 1992, and below).

The fact that defecation did not differ among the ISI groups and that Group 2.5 failed to differ significantly from Group USa on this measure suggests that defeca- tion is not as sensitive to changes in the independent variable as is freezing. The fact that Group USa defecated more than the No-shock control suggests that the US-alone procedure may be a more conservative control than the No-shock (i.e., CS-alone) procedure.

The evidence for conditioning with the immediate shock and for the inverted-U ISI function appears to bring one-trial context conditioning in line with other popular conditioning procedures. However, two criticisms raised during the review process weaken this conclusion. The first criticism was that the flashing pacing lamp mounted in front of the box may have served as a discrete or punctate CS. That punctate CS, and not the contextual cues, may have controlled the freezing that we observed. If so, then our evidence for the similarity of contextual conditioning and punctate $\mathrm{CS}$ conditioning is artifactual inasmuch as we merely studied another punctate CS.

The second criticism concerned the extent to which the immobility in the immediate-shock group reflects conditioned or unconditioned freezing. Because the Noshock control received $435 \mathrm{sec}$ of exposure to the context on Day 1 and the immediate-shock group received 
only $32.5 \mathrm{sec}$ of exposure, a reviewer suggested that any unconditioned freezing evoked by a novel context would habituate more in the no-shock control than in the immediate-shock group. The implication of this suggestion is that the freezing we observed following the immediate shock reflected an unconditioned effect of a relatively novel context and not a conditioned effect. This possibility seemed unlikely to us for two reasons. First, Group USa received no exposure to the test context on Day 1. Therefore, if Group 2.5 (immediate shock) was displaying only unconditioned freezing to a relatively novel context, Group USa should have shown even more freezing because its test context was even more novel. The results were just the opposite. Second, in a recently published report (Bevins \& Ayres, 1994, Experiment 1), we used a no-shock control that was matched for context exposure with an immediate-shock group. The immediateshock rats still froze more than the no-shock rats. Nevertheless, because of the two criticisms that were raised, we conducted the following experiment to assess their merit directly.

\section{EXPERIMENT 2}

Experiment 2 was designed to assess the two criticisms outlined above. To do so, we set out to replicate the inverted-U function by using the following ISIs: 2.5 , 120 , and $405 \mathrm{sec}$. Half of the rats at each ISI value had the pacing lamp present on both the conditioning and test days (same as Experiment 1). The other half, however, had the lamp present only on the test day. In the latter group, the pacing lamp could not serve as a punctate CS because it would not be experienced until the test day. Hence, under the no-lamp condition, the immediateshock procedure should not produce conditioned freezing and the long ISI should not weaken conditioning. On the other hand, if the pacing lamp did not serve as a discrete cue, then we should replicate the freezing results of Experiment 1 regardless of the presence or absence of the lamp on the conditioning day. We also equated the duration of context exposure between the no-shock control and the immediate group on Day 1. For both groups, the duration of that exposure was $32.5 \mathrm{sec}$. If unconditioned freezing was the only source of immobility in the immediate condition of Experiment 1, then we should find similar freezing in Groups 2.5 and No-shock.

\section{Method}

Subjects and Apparatus. The subjects were 80 albino rats obtained from Holtzman Company (Madison, W1). They were 80-81 days old at the start of the experiment. The males $(n=40)$ weighed from 395 to $499 \mathrm{~g}$. The females $(n=40$ ) weighed from 274 to $367 \mathrm{~g}$. The rats were housed and maintained as described previously. The apparatus was unchanged.

Procedure and Observations. The design was a $2 \times 4$ factorial. There were four shock conditions (no shock, 2.5-sec. 120-sec, and $405-\mathrm{sec}$ (S1). The other factor was the presence or absence of the pacing lamp on the conditioning day. Half of the rats in each shock condition had the lamp present on Day 1 (conditioning) and Day 2 (testing), thus replicating the lamp conditions of Experi- ment 1 . The other half had the pacing lamp present only on Day 2 (i.e., received conditioning in the absence of the lamp). The sexes were equally represented in each of the eight groups. The remaining procedural details were similar to those of Experiment 1 except for the following two changes: (1) Duration of exposure to the training context on Day 1 for the no-shock control was equated with that of Group 2.5 (i.e., $32.5 \mathrm{sec}$ ), and (2) we filmed the rats on both the conditioning and test days

Observations on the test day were exactly the same as in Experiment 1 . Filming the rats on the conditioning day allowed us to examine the unconditioned freezing evoked by the very first exposure to our standard conditioning/test context. We determined this level by scoring freezing in the 10 no-shock rats that had the pacing lamp present on the conditioning day. Also, by videotaping on the conditioning day, we were able to observe the behavior of each rat at the moment of shock onset. After previcwing the tapes, we defined mutually exclusive and exhaustive categories. Two main categories identified were "all paws on shock grid" and "only hind paws on shock grid." When a rat had all four paws on the grid, we scored whether the rat's behavior was directed toward a specific site on the grid floor (biting, licking, or sniffing) or was "undirected" (c.g., air sniffing or generally locomoting). When a rat had only its hind paws on the grid, we also scored general exploratory behavior and directed sniffing or biting at a wall or the ceiling of the box. When a rat was grooming, it tended to have only its hind paws on the grid.

\section{Results}

There was very little unconditioned freezing evoked by the context on the very first exposure $(M=2 \%$, Mdn $=0 \%$ ). In fact, only one of the 10 no-shock rats froze to any extent. Table 1 shows the frequency of each behavior scored at the moment of shock onset for each ISI group. For each ISI condition, we combined the rats from both lamp conditions (see below). ${ }^{2}$ Eighteen of the 19 rats scored in Group 2.5 had all four paws on the grid at the moment of shock. Moreover, these rats received shock while sniffing the air or initiating locomotor activity. Given the immediacy of the shock, the rats had almost no time to initiate a rear or to begin grid-directed behaviors. In the longer ISI groups (120 and $405 \mathrm{sec}$ ), about half of the rats were on all four paws at the moment of shock onset and the other half were on their hind paws. However, twice as many rats in Group 405 than in Group 120 were engaging in directed behaviors (including grooming) at the time of shock (14 vs. 7 rats). Interestingly, the rats in Groups 405 and 120 combined that were engaged in directed sniffing, biting, or licking at the moment of shock onset froze significantly less on the

Table 1

Frequency of Each Behavioral Category Scored at the Moment of Shock for Each ISI Group in Experiment 2

\begin{tabular}{lccc}
\hline \multicolumn{1}{c}{ Behavior } & $2.5-\mathrm{sec}$ ISI & $120-\mathrm{sec}$ ISI & $405-\mathrm{sec}$ ISI \\
& All Paws on Grid & & \\
General exploratory & 18 & 4 & 1 \\
Grid directed & 0 & 5 & 10 \\
& Hind Paws on Grid & & \\
General exploratory & 1 & 8 & 5 \\
Directed & 0 & 2 & 2 \\
Grooming & 0 & 0 & 2 \\
\hline
\end{tabular}




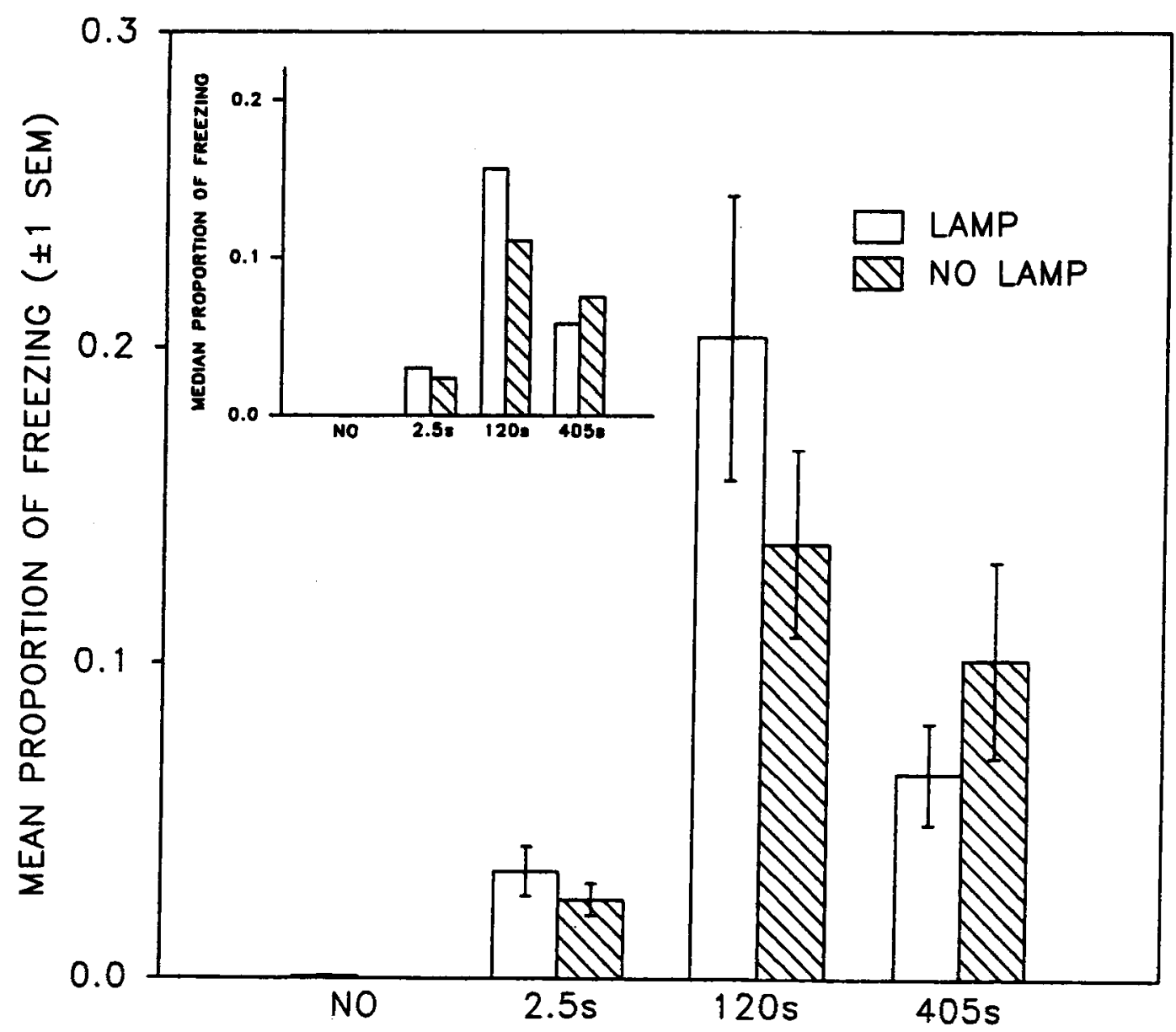

Figure 4. Mean proportion of freezing and the median level of freezing (inset graph) for each group in Experiment 2. Hatched bars denote groups that had the pacing lamp present only on the test day. Empty bars denote groups that had the pacing lamp present on both the conditioning day and the test day.

test day $(M=9 \%)$ than did rats not showing these directed behaviors $[M=18 \% ; F(1,37)=6.23]$.

Figure 4 shows the mean proportion of freezing and the median proportion of freezing (inset graph) for each group. The hatched bars denote the groups that did not have the pacing lamp on the conditioning day. Empty bars represent the groups that had the pacing lamp on both the conditioning and test days. A three-way ANOVA (ISI $x$ lamp $\times$ sex $)$ revealed a main effect of ISI $[F(2,48)=$ $14.10]$. No other effect was statistically significant $(F \mathrm{~s}<$ 1.8). Thus, the presence or absence of the lamp on the conditioning day did not differentially affect freezing at different ISIs. However, we again found the inverted-U ISI function. Since there was no effect of pacing lamp, we collapsed across this factor for subsequent analyses. A comparison of Group 405 with Group 120 revealed significantly less freezing in Group $405[t(38)=2.7]$. Also, there was significantly more freezing in Group 2.5 than in the no-shock control $(U=33)$.

Figure 5 shows the within-session distribution of freezing for the 20 rats averaged at each ISI value. The repeated measure ANOVA revealed significant main effects of group $[F(2,1083)=13.79]$ and bin $[F(19,1083)=$ $6.14]$. The group $\times$ bin interaction was also significant $[F(38,1083)=5.36]$. As in Experiment 1, Duncan's range tests were conducted to examine group differences. In Minute 1, Groups 2.5 and 120, which did not differ from each other, froze more than Group 405. In Minutes 2, 5, and 6, Group 120 froze more than Groups 2.5 and 405 . In Minutes 3 and 4, all groups differed from each other. In Minutes 7, 8, and 9, Group 120 froze more than Group 2.5; Group 405 did not differ from either group. In Minute 10, no group differences were detected. In sum, the freezing in the immediate-shock group (2.5-sec ISI) was concentrated early in the session, whereas freezing with the longer ISIs continued later into the 10 -min test session. By the end of testing, freezing was statistically comparable in all shock groups.

Figure 6 shows the mean number of boli and the median boli count (inset graph) for each group. A three-way ANOVA on the ISI groups revealed a main effect of ISI $[F(2,48)=10.63]$, denoting less defecation in Group 2.5 


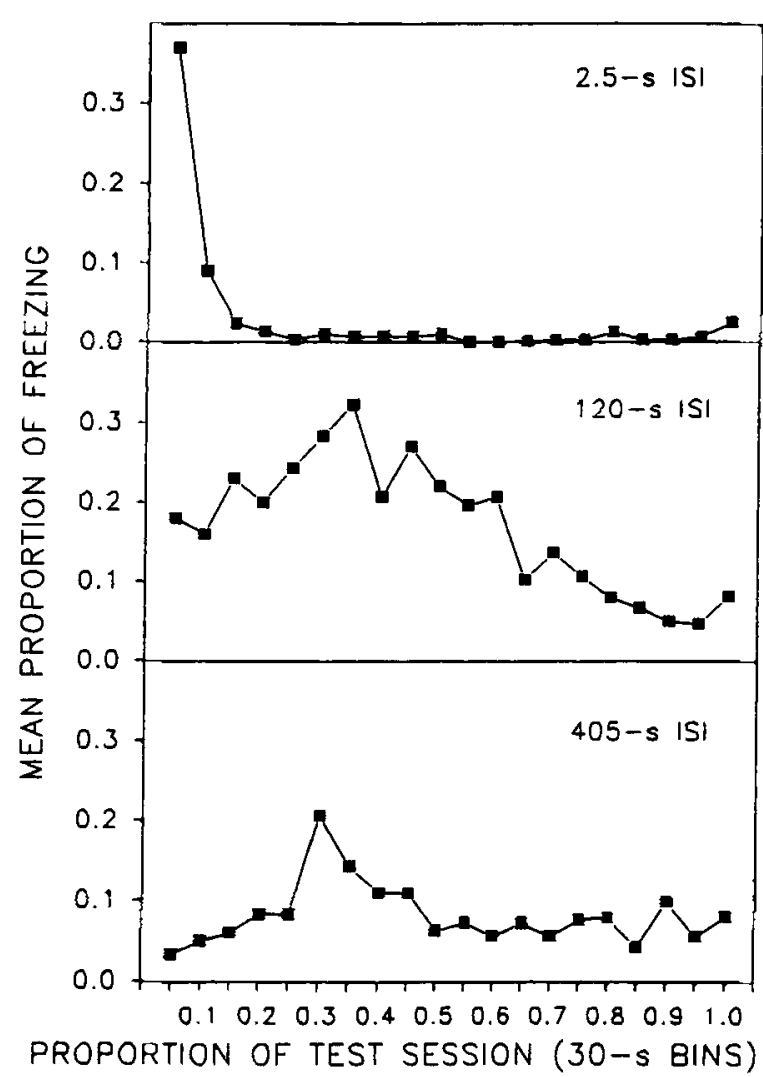

Figure 5. Mean proportion of freezing scores per 30-sec bin of the 10-min test session for each ISI group in Experiment 2.

than in Groups 120 and 405 . There was also a main effect of $\operatorname{sex}[F(1,48)=10.68]$. Females tended to defecate less $(M=3.8)$ than males $(M=5.9)$. No other effects were statistically significant $(F \mathrm{~s}<2.67)$. The data were combined for subsequent analyses as described previously. Defecation did not differ between Group 405 and Group $120(t<1)$. Group 2.5 defecated more than Group No-shock $(U=93.5)$ but less than Group 120 $[t(38)=3.98]$.

\section{Discussion}

Experiment 2 replicated the main freezing results of Experiment 1 . We found more freezing in the immediate-shock condition than in the no-shock control. This freezing occurred regardless of whether the pacing lamp was present or absent on the conditioning day. The immobility in Group 2.5 did not reflect unconditioned freezing evoked by the context. The no-shock control that was matched with Group 2.5 on context exposure time showed virtually no freezing on the test day. Furthermore, we found nearly zero freezing evoked by the context on the very first exposure. This last result argues against the possibility that the shock in Group 2.5 disrupted habituation to the context and that freezing on the test day reflected the unconditioned freezing resulting from a failure to habituate to the context. We also found a decrease in freezing at the longest ISI $(405 \mathrm{sec})$. The lack of a lamp $\times$ ISI interaction suggests that this downturn in conditioning did not rely upon the presence of the pacing lamp. The results from Groups 2.5 and 405 combined argue strongly against the notion that the pacing lamp in Experiment 1 had served as a punctate CS.

As in Experiment 1, when the ISI was very short $(2.5 \mathrm{sec})$ freezing was concentrated early in the test session. However, freezing was more evenly distributed throughout most of the session with longer ISIs. At the longer ISI values, there appeared to be a decrease in freezing in the later portion of the test period. This decrease may reflect context extinction.

The main effect of sex for freezing and the ISI $\times$ sex interaction for defecation, effects obtained in Experiment 1 , were not replicated here. Instead, we found a sex effect only for defecation (i.e., males defecated more than females). The differences in rearing history may be responsible for the inconsistencies of the sex effect. The rats in Experiment 1 were bred in our colony, and the rats in Experiment 2 were purchased directly from the Holtzman company at about 60 days of age. This difference in rearing history may also account for the difference in the defecation results of Experiments 1 and 2 . That is, in Experiment 1 , we found similar defecation in all groups that received a footshock, but in Experiment 2, Group 2.5 defecated less than did Groups 120 and 405.

\section{GENERAL DISCUSSION}

Three aspects of our results suggest that one-trial contextual fear conditioning obeys rules similar to those that govern the conditioning of punctate CSs. First, as in other conditioning situations with punctate CSs (Rescorla, 1988), one-trial context fear conditioning as measured by freezing is an inverted-U-shaped function of the ISI. Second, although contextual conditioning appears to be weak with very short ISIs, some conditioning does occur, just as it does with punctate CSs (Burkhardt \& Ayres, 1978; Heth \& Rescorla, 1973; Mahoney \& Ayres, 1976). Third, the shift in the within-session distribution of freezing as a function of ISI is similar to changes that are well documented in such Pavlovian conditioning preparations as the rabbit nictitating membrane response procedure (Schneiderman \& Gormezano, 1964) and aversive conditioning with goldfish (Bitterman, 1964).

What theoretical mechanisms can explain our results? Fanselow (1986, 1990; Fanselow et al., 1993) has offered several theories to explain the immediate-shock deficit. However, the downturn in the ISI function with long ISIs and the shift in the within-session distribution of freezing as a function of ISI have not been previously explained because they are relatively new findings. To explain our results, we shall borrow some ideas from one of Fanselow's accounts of the immediate-shock deficit. According to that account, a context comprises many elements. In order for conditioning to "the context" to occur, the elements must first be integrated into a "gestalt" or "dynamic stereotype," and a "representation" of that gestalt must be processed along with the US. Inte- 


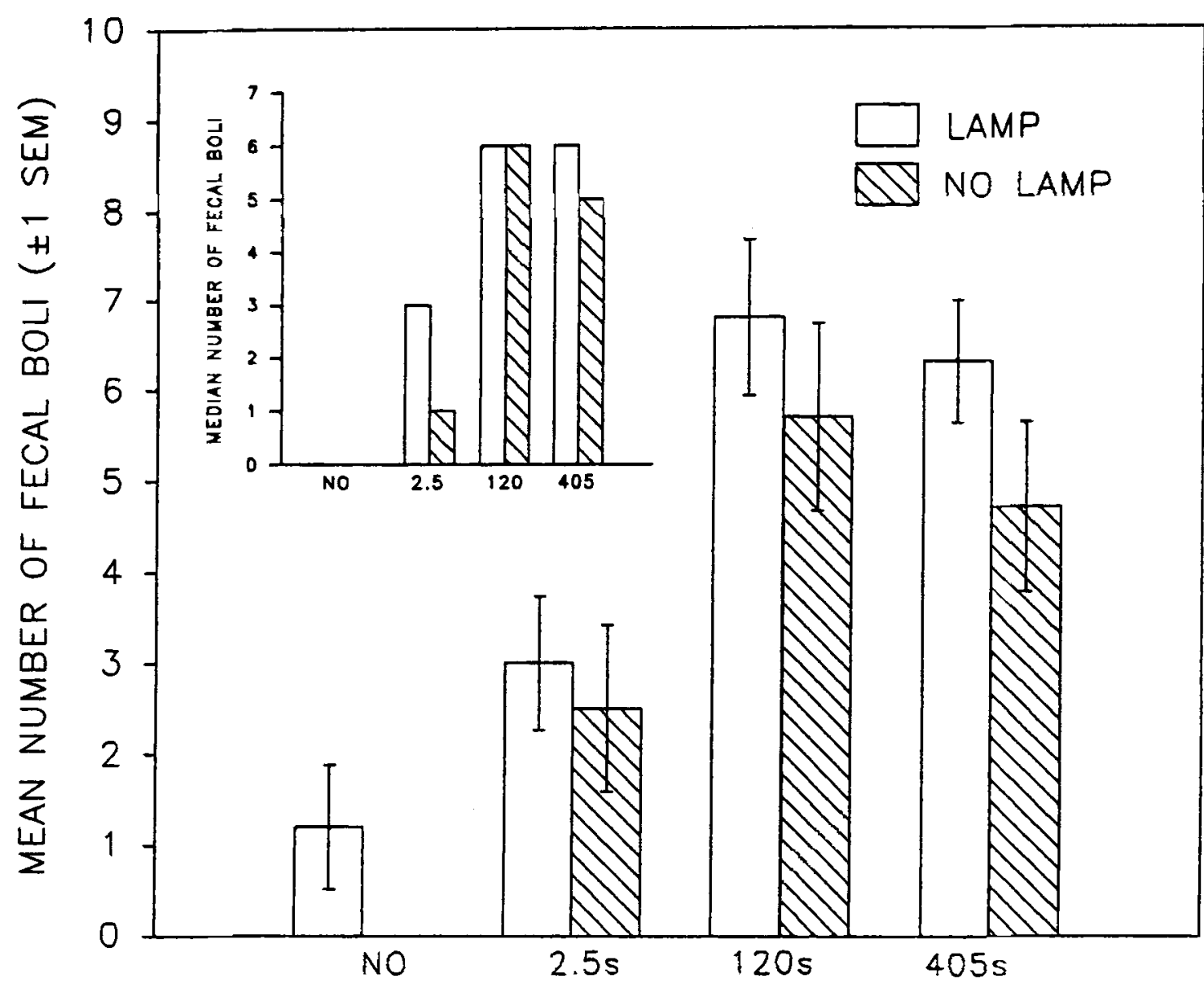

Figure 6. Mean number of feeal boli and the median number of boli (inset graph) for each group in Experiment 2. Hatched bars denote groups that had the pacing lamp present only on the test day. Empty bars denote groups that had the pacing lamp present on both the conditioning day and the test day.

gration of the elements takes time and may involve the formation of within-compound associations between the elements that make up the context. Like Fanselow, we assume that the context comprises many elements. We further assume that the rat can sample only a small subset of these elements prior to immediate shock. That small subset will then acquire conditioned value. On the next day, when the animal is tested, the context will be unlikely to evoke a conditioned response, because the rat is unlikely to sample the exact same subset of elements that was sampled prior to shock.

According to this view, however, the immediate-shock deficit need not be complete. In the test period, conditioned responding will increase with the proportion of the elements in the sample that are conditioned. Any factor that promotes the sampling of the same elements on the test occasion as on the conditioning occasion will increase the chances of detecting a conditioned response. Any factor that reduces conditioning to the sampled elements or promotes the sampling of new elements on the occasion of testing will reduce the chances of detecting a conditioned response. Detection of conditioned respond- ing is highly likely following intermediate ISIs because the animal has a chance to sample more of the stimulus elements prior to US onset. Assuming that this sampling has occurred in reasonable temporal contiguity to shock, all of these elements stand to gain conditioned value. If a large proportion of the available elements is then conditioned, a conditioned response on the occasion of testing becomes highly likely, because almost any sample at any moment will contain a high proportion of conditioned elements. With very long ISIs, attention to the elements of the context may decline or may become focused on a very narrow subset of these elements. This is suggested by our observations that rats in Group 405 were twice as likely to be directing their behavior at a specific set of stimuli within the context. That is, these rats were biting, sniffing, or licking a specific site at the moment of shock onset. By engaging in these behaviors, the rats reduce the probability of sampling a broad range of the contextual elements shortly before shock onset. Consistent with this observation, rats showing such directed behavior at the moment of shock onset subsequently froze less than did rats not displaying these behaviors. 
The shift in the within-session distribution of freezing as a function of ISI is explainable in terms of the analysis just described. Among the elements that stand to be conditioned by immediate shock are transportation cues and box-placement cues. By transportation cues, we refer to those handling cues specific to transporting the rat from the colony to the conditioning/test room. By boxplacement cues, we refer to the manner in which the rat is held when it is placed in the box and to the rat's exact location in the box when first placed there. Because these cues tend to be associated with the start of a session, they are likely to be conditioned by immediate shock and to evoke freezing in the test session only early in that session. These cues are less likely to have been recently sampled prior to delayed shock. The cues that are sampled prior to delayed shock are those that tend to be present throughout the session. The result would be that freezing in the test session should be more broadly distributed and not confined to the start of the session.

Why do we obtain evidence for conditioning (albeit weak) following immediate shock, whereas Fanselow, in many experiments, has never found evidence for any conditioning whatsoever? We shall consider four possibilities.

1. Although we profess to use the same system of scoring freezing as does Fanselow, there may be some subrle difference between our procedures, a difference of which we are unaware. On this point, it must be emphasized that all of the scoring in both Fanselow's laboratory and ours is done without knowledge of what treatment the subject has received. There can thus be no bias in either laboratory. If there is some difference in our scoring procedures (and we do not believe there is), the only possible conclusion is that our technique is more sensitive to the conditioning that results from immediate shock. This possibility receives some support from the study by Blanchard et al. (1976), who first described the immediateshock deficit but also reported evidence for some (albeit weak) conditioning in the immediate-shock condition. Their index of conditioning, which involved some measurement of movement time, was also different from that used in Fanselow's laboratory. On a related point, because the scoring of freezing is not entirely an objective matter, one might wish for some completely objective measure of conditioning following immediate versus delayed shock. Research in progress in our laboratory has used such measures, and they too provide evidence for conditioning after immediate shock (see Bevins, 1993; cf. Fanselow et al., 1994; Kiernan, Westbrook, \& Cranney, 1995).

2. Our shock may have been more effective than that used by Fanselow even though it was of the same nominal intensity and duration. We make this suggestion because most of Fanselow's work has involved delivering shock through Grason-Stadler scramblers. We, in contrast, used a Hoffman-Fleshler relay scrambler. Both types of scramblers have been used for years in our laboratory, and we believe that the Hoffman-Fleshler scrambler delivers a more effective shock. Some support for this idea comes again from the work of Blanchard et al., who used a much higher nominal shock intensity than was used in either Fanselow's laboratory or ours and who also reported evidence for some conditioning following immediate shock.

3. Fanselow's transportation cues received more preexposure than did ours and were thus likely to show retarded conditioning (Lubow, 1989). Although rats were handled extensively prior to experimentation in both our laboratory and Fanselow's, Fanselow's handling procedure involved transporting each rat to the laboratory on 10 occasions prior to conditioning. Because transportation cues are very likely to be sampled just prior to immediate shock and again at the start of the test session, any procedure that retarded conditioning to those cues would weaken the conditioned effects of immediate shock.

4. There may be a difference in box-placement cues in our laboratory versus Fanselow's. In our research, pains were taken to ensure that, insofar as possible, boxplacement cues were identical for every rat on both days of the procedure. The box-placement cues are likely to be sampled just prior to immediate shock. They are also likely to be sampled at the start of the test session. If the box-placement cues were less consistent across days in Fanselow's laboratory, then the placement cues that were sampled at the start of the test session would likely differ from those that were sampled prior to shock, with a consequent reduction in conditioned responding early in the test session.

With regard to the last two possibilities, we assume that transportation cues and box-placement cues are contextual cues. They are an inev itable part of the context in much the same way that the walls of the box are an inevitable part of the context. However, a case could be made that transportation cues and box-placement cues are not contextual cues at all, but are, instead, punctate CSs. Unlike the walls of the box, they are present more at the start of a session than in the middle or end of the session. If a concensus develops that transportation cues and box-placement cues are punctate, and if it is only these cues that control freezing following immediate shock, then it may indeed be true that there is no contextual conditioning following immediate shock. However, the results of the original procedure used by Blanchard et al. to demonstrate the immediate-shock deficit argue against this possibility. In that procedure, the observation test period was a period of time following the shock, not a period of time in a session on the next day. Although transportation and box-placement cues in their procedure were likely to have acquired conditioned value, they were unlikely to have been sampled during the test. By forcing the animal to jump around and change its tocation in the box, the shock would virtually ensure that cues other than those associated with transportation and box placement be sampled during the test period. It is of interest, therefore, that Blanchard et al., like us, found evidence for some (albeit weak) conditioning following immediate shock.

We should mention that Fanselow et al. (1993) proposed a physiological model that provided an account of 
the absence of conditioning with the immediate shock. According to this model, for contextual conditioning to occur, the amygdala must be conjointly activated by shock input and contextual input. The immediate-shock deficit is due to the arrival of immediate-shock input at the amygdala before the arrival of contextual input from the hippocampus. This model assumes that there is no conditionable stimulus input at the moment of the immediate shock. Given the evidence for conditioning from the Blanchards' and our laboratory, this assumption needs to be reevaluated.

As a final comment, we note that after repeatedly finding no evidence for contextual conditioning following immediate shock, Fanselow (1990) suggested that the immediate-shock procedure be used as a control for sensitization and pseudoconditioning, providing a baseline against which the conditioned effects of more delayed shocks could be evaluated. In short, he offered the immediate-shock procedure as a nonassociative control procedure for the study of contextual conditioning. That suggestion is reminiscent of an earlier one by Beecroft (1966, p. 19), who proposed that 0-sec ISIs (simultaneous conditioning procedures) should leave punctate CSs neutral and thus provide an appropriate control procedure for the study of punctate CS conditioning. Both suggestions, if followed, would have the effect of eliminating simultaneous conditioning as a phenomenon of empirical interest.

\section{REFERENCES}

Beecroft, R. S. (1966). Classical conditioning. Goleta, CA: Psychonomic Press.

Bevins, R. A. (1993). A simple model system for studying Pavlovian conditioning: One-trial context fear conditioning. Unpublished doctoral dissertation, University of Massachusetts, Amherst.

Bevins, R. A., \& Ayres, J. J. B. (1994). Deficit in one-trial context conditioning not due to opioid analgesia. Pharmacology, Biochemistry \& Behavior, 49, 183-186.

BitTERMAN, M. E. (1964). Classical conditioning in the goldfish as a function of the CS-US interval. Journal of Comparative \& Physiological Psychology, 58, 359-366.

Blanchard, R. J., Fukunaga, K. K., \& Blanchard, D. C. (1976), Environmental control of defensive reactions to footshock. Bulletin of the Psychonomic Society, 8, 129-130.

BURKHARDT, P. E., \& AYRES, J. J. B. (1978). CS and US duration effects in one-trial simultaneous fear conditioning as assessed by conditioned suppression of licking in rats. Animal Learning \& Behavior, 6, 225-230.

FANSELOW, M. S. (1986). Associative vs topographical accounts of the immediate shock-freezing deficit in rats: Implications for the response selection rules governing species-specific defensive reactions. Learning \& Motivation, 17, 16-39.

FANSELOw, M. S. (1990). Factors governing one-trial contextual conditioning. Animal Learning \& Behavior, 18, 264-270.

Fanselow, M. S., DeCol.A, J. P., \& YounG, S. L. (1993). Mechanisms responsible for reduced contextual conditioning with massed unsignaled unconditional stimuli. Journal of Experimental Psychology: Animal Behavior Processes, 19, 121-137.
Fanselow, M. S., Landeira-Fernandez, J., DeCola, J. P., \& Kim, J. J. (1994). The immediate-shock deficit and postshock analgesia: Implications for the relationship between the analgesic CR and UR. $A n$ imal Learning \& Behavior, 22, 72-76.

Gibbon, J., Baldock, M. D., Locurto, C., Gold, L., \& Terrace, H. S. (1977). Trial and intertrial durations in autoshaping. Journal of Experimental Psychology: Animal Behavior Processes, 3, 264-284.

Hawkins, R. D., Carew, T. J., \& Kandel, E. R. (1986). Effects of interstimulus interval and contingency on classical conditioning of the Aplysia siphon withdrawal reflex. Journal of Neuroscience, $\mathbf{6}$, 1695-1701.

Heth, C. D., \& Rescorla, R. A. (1973). Simultaneous and backward fear conditioning in the rat. Journal of Comparative \& Physiological Psychology, 82, 434-443.

Hoffman, H. S., \& Fleshler, M. (1962). A relay sequencing device for scrambling grid shock. Journal of the Experimental Analysis of Behavior, 5, 329-330.

Kiernan, M. J., Westbrook, R. F., \& Cranney, J. (1995). Immediate shock, passive avoidance, and potentiated startle: Implications for the unconditioned response to shock. Animal Learning \& Behavior, 23, 22-30

Luвow, R. E. (1989). Latent inhibition and conditioned attention theory. New York: Cambridge University Press.

Maes, J. H. R., \& Vossen, J. M. H. (1992). One-trial aversive conditioning to contextual cues: Effects of time of shock presentation on freezing during conditioning and testing. Bulletin of the Psvchonomic Society, 30, 403-406.

Mahoney, W. J., \& Ayres, J. J. B. (1976). One-trial simultaneous and backward fear conditioning as reflected in conditioned suppression of licking in rats. Animal Learning \& Behavior, 4, 357-362.

MCAllister, W. R. (1953). Eyelid conditioning as a function of the CS-US interval. Journal of Experimental Psychology, 45, 41 7-422.

RESCORLA, R. A. (1967). Pavlovian conditioning and its proper control procedures. Psychological Review, 74, 71-80

Rescorla, R. A. (1988). Behavioral studies of Pavlovian conditioning. Annual Review of Neuroscience, 11, 329-352.

Schneiderman, N., \& Gormezano, I. (1964). Conditioning of the nictitating membrane of the rabbit as a function of CS-US interval. Journal of Comparative \& Physiological Psychology, 57, 188-195.

Smith, M. C., Coleman, S. R., \& Gormezano, I. (1969). Classical conditioning of the rabbit's nictitating membrane response at backward, simultaneous, and forward CS-US intervals. Journal of Comparative \& Physiological Psychology, 69, 226-231.

Williams, D. A., Frame, K. A., \& Lolordo, V. M. (1992). Discrete signals for the unconditioned stimulus fail to overshadow contextual or temporal conditioning. Journal of Experimental Psychology: Animal Behavior Processes, 18, 41-55.

WILSON, K. V. (1956). A distribution-free test of analysis of variance hypotheses. Psychological Bulletin, 53, 96-101.

YEO, A. G. (1974). The acquisition of conditioned suppression as a function of interstimulus interval duration. Quarterly Journal of Experimental Psychology, 26, 405-416.

\section{NOTES}

1. The main conclusions based on statistical analyses did not vary whether a parametric ANOVA or a nonparametric ANOVA (Wilson, 1956) was used to analyze the ISI group data.

2. Because of filming errors, we lost 1 rat in the 2.5 -sec ISI condition and one in the 120 -sec ISI condition.

(Manuscript received March 4, 1994; revision accepted for publication February 22, 1995.) 